\title{
Efeito da cobertura de resíduo da cultura do milho na evaporação da água do solo ${ }^{1}$
}

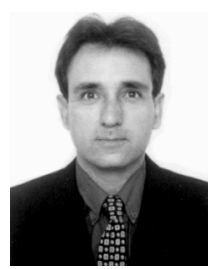

Paulo S. L. de Freitas ${ }^{2}$, Everardo C. Mantovani ${ }^{3}$, Gilberto C. Sediyama ${ }^{4} \&$ Luiz C. Costa $^{4}$

\author{
1 Parte da tese de doutorado do primeiro autor \\ 2 DAG, Universidade Estadual de Maringá. Av. Colombo 5790, CEP 87020-900, Maringá, PR. E-mail: pslfreitas@uem.br (Foto) \\ 3 DEA/UFV. CEP 3657-000, Viçosa, MG. E-mail: everardo@ufv.br \\ 4 DEA/UFV. E-mail: sediyama@ufv.br \\ ${ }^{5}$ DEA/UFV. E-mail: I.costa@ufv.br
}

Protocolo 147 - 14/10/2002 - Aprovado em 6/2/2004

\begin{abstract}
Resumo: No presente trabalho, analisou-se a influência do resíduo de cultura do milho na evaporação da água do solo. Os tratamentos constaram de três taxas de resíduo de culturas, 0, 50 e $100 \%$ da matéria seca produzida pela cultura em sistema irrigado, de três demandas evaporativas de 3, 6 e $8 \mathrm{~mm} \mathrm{~d}^{-1}$ e de duas classes texturais de solo, areia franca e muito argiloso, contendo $84 \%$ de areia e $76 \%$ de argila, respectivamente. O experimento foi conduzido em laboratório, com o solo acondicionado em colunas de PVC de $45 \mathrm{~cm}$ de altura e $20 \mathrm{~cm}$ de diâmetro. As demandas evaporativas de 3, 6 e $8 \mathrm{~mm} \mathrm{~d}^{-1}$ foram obtidas por meio de lâmpadas incandescentes, dispostas sobre as colunas de solo, a uma altura de $10 \mathrm{~cm}$. A coleta de dados foi realizada diariamente, por meio da pesagem das colunas de solo, utilizando-se uma balança digital com capacidade máxima de 32.100 g e precisão de $1 \mathrm{~g}$. A taxa de evaporação da água do solo descoberto apresentou comportamento distinto para as três demandas evaporativas utilizadas. As reduções na evaporação da água do solo para as taxas de $100 \%$ da matéria seca produzida, para a cultura do milho $\left(10.000 \mathrm{~kg} \mathrm{ha}^{-1}\right)$, para

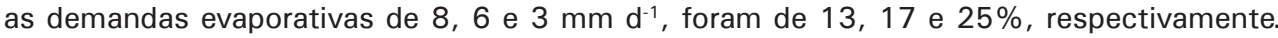

Palavras-chave: resíduos culturais, demanda evaporativa, Zea mays, $L$.

\section{Influence of the corn crop residue on the soil water evaporation}

\begin{abstract}
In the present work, the influence of the corn crop residue on the soil water evaporation was analyzed. The experimental treatments consisted of three rates of corn residue (stalk), 0, 50 and $100 \%$ of the dry matter yield by irrigated corn crop system; three evaporative demands of 3 , 6 , and $8 \mathrm{~mm} \mathrm{~d}^{-1}$; and two soils of different texture, sandy loam and clay soil, with $84 \%$ of sand and $76 \%$ of clay, respectively. The experiment was carried out in laboratory, with the soil conditioned in PVC columns of $45 \mathrm{~cm}$ in height and $20 \mathrm{~cm}$ in diameter. The water evaporative demands of 3 , 6 and $8 \mathrm{~mm} \mathrm{~d}^{-1}$ were obtained by means of incandescent lamps, fixed on the soil columns at a height of $10 \mathrm{~cm}$. The daily data collection was accomplished by means of weighing the soil columns, using a digital scale with maximum capacity of $32,100 \mathrm{~g}$ and precision of $1.0 \mathrm{~g}$. The direct water evaporation rate from the soil columns presented different behavior for the three water evaporative demands. The reductions in the soil water evaporation for the dry matter yield rates of $100 \%$, for the corn crop equivalent to $10.000 \mathrm{~kg} \mathrm{ha}^{-1}$, for the water evaporative demands of 8,6 , and $3 \mathrm{~mm} \mathrm{~d}^{-1}$, were 13,17 and $25 \%$, respectively.
\end{abstract}

Key words: crop residue, water evaporative demand, Zea mays, L.

\section{INTRODUÇÃO}

O sistema de plantio direto, em uso há vários anos no Brasil, vem sendo implementado em grande escala. Na safra 1999/ 2000 , foram plantados aproximadamente 13 milhões de hectares em plantio direto. Este crescimento acentuado se deve a vários aspectos: à importância econômica para os produtores e efeitos benéficos sobre as propriedades do solo, com o maior controle da erosão, à redução das perdas de água por escoamento superficial e ao conseqüente aumento da disponibilidade hídrica para as culturas.

A utilização de equipamentos pesados no preparo convencional de solo, em sistema de produção agrícola sob irrigação, pode intensificar a formação de camada compactada, comprometendo a infiltração da água pluvial e de irrigação e, em muitas situações, ocorrendo o escoamento superficial. As avaliações 
das condições de umidade do solo em sistemas de plantio direto e convencional, mostraram diferenças acentuadas do conteúdo de água no solo até 30 dias após a semeadura, período em que o cultivo se aproxima da fase de cobertura completa do solo (Unger, 1978; Unger \& Wiese, 1979; Alencar, 1988; Andrade, 1992; Bordovsky et al., 1994), resultados estes não encontrados por Unger (1994) e Alvarenga (1996).

A evaporação é o maior componente do balanço da água para áreas com culturas irrigadas ou de sequeiro. A evaporação acumulada da água do solo representou mais da metade da evapotranspiração da cultura do tomate com dossel parcial (Tanner \& Jury, 1976), proporção esta também encontrada para a cultura do algodão irrigado (Al-Khafaf et al., 1978). Klocke et al. (1985) relataram que a evaporação correspondeu a 30\% da evapotranspiração para a cultura do milho irrigado, e Lascano et al. (1987) encontraram a mesma proporção para a cultura do algodão.

Lascano \& Baumhardt (1996) compararam o efeito do sistema convencional de plantio com o de um sistema com resíduo de trigo sobre a superfície na evaporação da água do solo, em uma lavoura de algodão. Os autores verificaram, ainda, que a evaporação foi $50 \%$ da evapotranspiração no sistema convencional e $31 \%$ no sistema com resíduo da cultura de trigo.

A taxa de evaporação da água do solo pode ser agrupada em diferentes estágios, em que o primeiro pode durar de um a três dias, conforme a magnitude da taxa de evaporação que, nesta fase, depende das condições atmosféricas externas, sendo esta de aproximadamente $90 \%$ da demanda evaporativa; a duração do primeiro estágio é influenciada pela taxa de evaporação, pela profundidade do solo e pelas propriedades hidráulicas do solo; durante o segundo estágio, a superfície torna-se seca e a evaporação ocorre abaixo da superfície (Jensen et al., 1990).

Para calcular a evaporação da água do solo, Ritchie (1972) estabeleceu os índices $U$ e $\alpha$. O primeiro refere-se à quantidade de água evaporada no primeiro estágio; portanto, depende das características do solo; já o segundo corresponde à taxa de evaporação da água do solo no segundo estágio. Quando medido em campo, o valor de $\mathrm{U}$ varia de aproximadamente 5 $\mathrm{mm}$, para solo arenoso, a $14 \mathrm{~mm}$, para solo de textura mais argilosa (Ritchie \& Jonhson, 1990).

Bond \& Willis (1970) estudaram a influência da demanda evaporativa na duração do primeiro estágio e na magnitude da evaporação acumulada. $\mathrm{O}$ experimento foi conduzido em laboratório, utilizando-se colunas com solo franco-arenoso. Os tratamentos constaram de seis demandas evaporativas, que variaram de 4,7 a 13,4 $\mathrm{mm} \mathrm{d}^{-1}$. Com o aumento da demanda evaporativa, a quantidade de água evaporada no primeiro estágio diminuiu; entretanto, a quantidade de água evaporada nos 25 dias seguintes após ter cessado o primeiro estágio, aumentou com a elevação da demanda evaporativa. Quando esta é superior a $10 \mathrm{~mm} \mathrm{~d}^{-1}$, a duração do primeiro estágio é muito curta, isto é, de uns dois dias, enquanto para uma demanda que se chegava $1 \mathrm{~mm} \mathrm{~d}^{-1}$, a duração do primeiro estágio é de mais ou menos 50 dias. Também Reichardt (1968) encontrou que a duração do primeiro estágio depende da taxa de evaporação.
Em condições irrigadas ou de sequeiro, o conhecimento da redução na evaporação da água do solo e na evapotranspiração da cultura permitirá a realização do balanço de água no solo e a determinação das necessidades de água das culturas.

A avaliação da redução da evaporação da água no solo em sistema de plantio direto sob irrigação, é de fundamental importância para o manejo da água. Assim, realizou-se o presente trabalho com o objetivo de determinar a influência do resíduo da cultura do milho na evaporação da água do solo, sob diferentes demandas evaporativas, para dois solos com características físico-hídricas distintas, em colunas de solo em condições de laboratório.

\section{MATERIAL E MÉTODOS}

O experimento foi realizado no Laboratório de Hidráulica do Departamento de Engenharia Agrícola, pertencente à Universidade Federal de Viçosa, MG.

As colunas de solo foram construídas com $45 \mathrm{~cm}$ de altura, utilizando-se tubos de PVC com $20 \mathrm{~cm}$ de diâmetro nominal para essas dimensões se adequarem à capacidade da balança de precisão, mas sem comprometer as condições do trabalho; já as colunas foram perfuradas nas bases, para possibilitar a drenagem da água do solo. Foram construídas 39 colunas de PVC para a realização do experimento, sendo três destas sem perfurações nas bases; depois de construídas, cada coluna foi pesada sem solo, numa balança com capacidade mínima de 50 g, máxima de $32.100 \mathrm{~g}$ e precisão de $1 \mathrm{~g}$.

No experimento foram utilizadas duas classes texturais de solos um procedente de Janaúba, MG (projeto Gorutuba, pertencente à Companhia de Desenvolvimento do Vale do São Francisco - CODESVAF) e o outro da Estação Experimental de Coimbra, MG (da Universidade Federal de Viçosa). Os solos foram destorroados, peneirados e secos ao ar, antes de serem colocados dentro das colunas. Os dois solos utilizados foram classificados, de acordo com sua textura, como muito argiloso e areia franca, cuja composição granulométrica está apresentada na Tabela 1. Os solos foram colocados nas colunas em camadas e, então, as colunas foram vibradas manualmente, para acondicionamento do solo e, após o ser preenchimento, realizou-se outra pesagem, objetivando-se determinar o peso das colunas com solo, para efetuar o cálculo da densidade média de cada solo.

Tabela 1. Análise granulométrica

\begin{tabular}{ccccc}
\multirow{2}{*}{ Solo } & Areia Grossa & Areia Fina & Silte & Argila \\
\cline { 2 - 5 } & \multicolumn{5}{c}{$\mathrm{g} \mathrm{kg}^{-1}$} \\
\hline Areia franca & 250 & 590 & 110 & 50 \\
Muito argiloso & 60 & 30 & 150 & 760 \\
\hline
\end{tabular}

A densidade média do solo muito argiloso foi de 0,98 e a do solo areia franca, de 1,19. As curvas de retenção da água no solo estão apresentadas na Figura 1.

Cada fileira constou de 13 colunas, das quais 12 colunas foram preenchidas com solo (seis contendo solo muito argiloso e as outras seis solo areia franca) e um recipiente com água, para determinação da demanda evaporativa. 


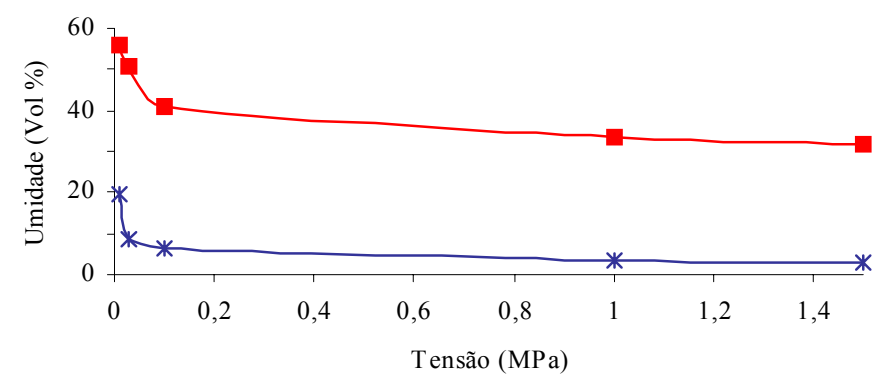

- Muito Argiloso $\rightarrow$ - Areia Franca

Figura 1. Curvas de retenção para duas classes de solo: areia franca e muito argiloso

Visando-se promover a evaporação somente nas superfícies dos solos e da água, construíram-se três suportes para lâmpadas, cada um com $7 \mathrm{~m}$ de comprimento e 15 bocais, e lâmpadas de mesma potência; 13 destes para evaporar água e dois dispostos nas extremidades para uniformizar a demanda atmosférica naquelas colunas de solo das extremidades. Foram adotados um espaçamento de $0,5 \mathrm{~m}$ entre as colunas e uma distância de 1,0 m entre as fileiras. Sobre cada uma das fileiras de colunas posicionou-se um suporte, em que cada lâmpada foi colocada acima do centro de cada coluna e o bocal foi instalado na estrutura, distando $57 \mathrm{~cm}$ do piso, de modo que as lâmpadas distassem $10 \mathrm{~cm}$ da superfície evaporante. As demandas evaporativas de 3,6 e $8 \mathrm{~mm} \mathrm{~d}^{-1}$ foram obtidas ao se utilizar lâmpadas com 40, 100 e $150 \mathrm{~W}$ de potência, cujo sistema era acionado por um temporizador, que permitia que as lâmpadas permanecessem acesas por 12 horas durante o dia e fossem desligadas à noite.

\section{Delineamento experimental}

O experimento foi composto por 39 colunas de PVC, sendo 36 preenchidas com duas classes de solo (18 colunas com solo muito argiloso e as demais com o solo areia franca) e três colunas de PVC cheias com água, para determinar a demanda evaporativa. $\mathrm{O}$ experimento foi em fatorial de $3 \times 3 \times 2$, os tratamentos constituídos de três demandas evaporativas, três taxas de resíduos culturais e duas classes de solo. O delineamento experimental foi em blocos casualisados, com duas repetições. As colunas foram distribuídas ao acaso, de modo que o centro delas estivesse situado abaixo da respectiva lâmpada incandescente.

Para definição das taxas de resíduo, considerou-se uma produtividade média da cultura do milho produzida em sistema irrigado e, também, que a cultura do milho produz, em média, $10.000 \mathrm{~kg} \mathrm{ha}^{-1}$ de resíduo, cujo valor médio depende de muitos fatores, como genéticos, edáficos, práticas culturais e climáticos.

No experimento utilizaram-se 50 e $100 \%$ da quantidade de resíduo da cultura. Em condições experimentais, torna-se difícil trabalhar com quantidades de resíduo da ordem de $t$ ha $^{-1}$ mas, com o valor da área de seção transversal das colunas de PVC $\left(314,16 \mathrm{~cm}^{2}\right)$ pode-se converter a quantidade de resíduo existente em 1 ha em $g$ coluna $^{-1}$. Para a cultura do milho obtiveram-se 15,7 e $31,4 \mathrm{~g}$ de resíduo por coluna, respectivamente, o que corresponde a 50 e $100 \%$ da quantidade da cobertura de resíduo, disposta sobre o solo.
Antes de ser colocado nas colunas, o resíduo foi disposto na plataforma de colheitadeira, para se obter as condições de campo e, depois, distribuído em suas superfícies de modo uniforme, recobrindo igualmente os solos. As superfícies dos solos para os tratamentos com e sem resíduo situaram-se $2 \mathrm{~cm}$ abaixo da borda da coluna de PVC; em seguida, procedeu-se à saturação das 36 colunas de solo, que foram tampadas com plástico e deixadas em repouso por cinco dias, de modo que a água excedente fosse drenada. No momento da saturação, os tratamentos sem resíduo na superfície foram protegidos com um disco de feltro, para reduzir o impacto direto da água, o que causaria, conseqüentemente, desprendimento de argila e ocasionaria o selamento do solo. O plástico foi utilizado para não permitir perdas por evaporação.

Decorrido o período de drenagem, acionou-se o sistema de lâmpadas, que permaneciam em funcionamento por 12 horas, visando simular o fotoperíodo.

\section{Obtenção dos dados}

A coleta de dados foi realizada durante 28 dias. Com a finalidade de se obter maior regularidade e precisão nos resultados, fixou-se um horário para a coleta de dados ( 8 da manhã). Diariamente, cada coluna de solo foi pesada individualmente, numa balança com precisão de $1 \mathrm{~g}$ e, nas colunas destinadas à determinação das demandas evaporativas realizou-se a reposição da água evaporada. Para manter a regularidade nos resultados, estabeleceu-se uma seqüência para as pesagens.

\section{Aplicação de lâmina d'água simulando uma irrigação ou precipitação pluvial}

Durante 21 dias avaliou-se a evaporação da água do solo com e sem resíduo, para diferentes demandas evaporativas (3, 6 e $8 \mathrm{~mm} \mathrm{~d}^{-1}$ ) para a condição de solo saturado, e deixado drenar por cinco dias. Visando-se estudar o comportamento dos distintos tratamentos perante a condição de simulação de irrigação, aplicaram-se lâminas d'água nas superfícies das colunas de solo. As colunas de solo com e sem resíduo da cultura do milho receberam lâminas d'água de $20 \mathrm{~mm}$, isto é, um volume de $628 \mathrm{~mL}$.

\section{Medição da temperatura do solo}

Mediu-se a temperatura do solo para acompanhar sua variação com redução da umidade do solo; para isto, foram construídas duas colunas de PVC com as mesmas características das utilizadas no experimento já descrito. Termopares foram inseridos em orifícios perpendiculares à parede da coluna de PVC, até o seu centro, a uma distância de 1, 3, 5, 10, 20 e $30 \mathrm{~cm}$ da superfície do solo sem resíduo. Cada coluna foi preenchida com uma classe de solo cujo acondicionamento seguiu o mesmo procedimento nas demais colunas; logo após, os solos foram saturados e cobertos com plástico e depois de cinco dias de drenagem, as colunas de solo foram submetidas a uma demanda evaporativa de aproximadamente $8 \mathrm{~mm} \mathrm{~d}^{-1}$.

A aquisição dos dados de temperatura foi realizada automaticamente, por meio de uma aquisidora de dados acoplada a um computador. A temperatura foi medida em intervalos de $1 \mathrm{~h}$, em um período de $24 \mathrm{~h}$; em seguida, o sistema foi desligado por $24 \mathrm{~h}$, e religado. 
Umidade dos solos nas colunas no primeiro dia de pesagem

Depois de se preencher as colunas com solo seco ao ar, elas foram pesadas. Instalado o experimento e após cinco dias da saturação das colunas de solo, iniciaram-se as pesagens. Com o peso de cada coluna no primeiro dia do início das pesagens, para cada período de coleta de dados determinouse a umidade em cada coluna, pelas diferenças de peso das colunas sem solo, do solo seco ao ar e do peso desta no primeiro dia do início da evaporação da água do solo.

\section{RESULTADOS E DISCUSSÃO}

\section{Demanda evaporativa de $8 \mathrm{~mm} \mathrm{~d}^{-1}$}

A evaporação da água do solo ocorrida no tratamento de demanda evaporativa de aproximadamente $8 \mathrm{~mm} \mathrm{~d}^{-1}$, mostrouse distinta para solos areia franca e muito argiloso, sem resíduo na superfície (Fig. 2A). Para os primeiros dias, solo areia franca, a evaporação foi superior à ocorrida em solo muito argiloso. A evaporação decresceu acentuadamente nos primeiros dias, enquanto para o solo areia franca esta se manteve em níveis elevados até o quinto dia, quando comparada à demanda evaporativa, e então ocorreu redução acentuada. A evaporação da água no solo areia franca foi superior à do solo muito argiloso, até o $15^{\circ}$ dia, mas a partir do qual ocorreu o inverso. O solo muito argiloso passou, após dois dias do início da evaporação a apresentar fendas, que promoveram a redução da evaporação da água do solo, como pode ser observado na Figura 2A. Os dois solos permaneceram no primeiro estágio de evaporação nos primeiros três dias, época em que esta depende somente da demanda evaporativa; após este período, a evaporação da água do solo passou para o segundo estágio, época em que ela depende das características hidráulicas do solo.

Para os tratamentos com 5.000 e $10.000 \mathrm{~kg} \mathrm{ha}^{-1}$ de resíduo, a evaporação da água do solo permaneceu no primeiro estágio por todo o período, resultados estes concordantes com Bond \& Willis (1970) e Reichardt (1968).

A temperatura do solo elevou-se com o decréscimo de sua umidade, tendo a temperatura máxima para o solo muito argiloso sido de $54^{\circ} \mathrm{C}$ e, para areia franca, de $42,7^{\circ} \mathrm{C}$, para a profundidade de $1 \mathrm{~cm}$; para as profundidades de 3,5 e $10 \mathrm{~cm}$, as diferenças de temperatura foram de aproximadamente $3{ }^{\circ} \mathrm{C}$. Para as profundidades de 20 e $30 \mathrm{~cm}$, as temperaturas do solo areia franca foram superiores às do muito argiloso, em aproximadamente $1^{\circ} \mathrm{C}$. As temperaturas foram mais elevadas no solo muito argiloso, ressaltando-se que este apresenta coloração avermelhada, enquanto o solo areia franca, com umidade próxima à capacidade de campo, apresenta coloração escura. A baixa umidade na superfície do solo faz com que a transferência de água das camadas abaixo da superfície para atmosfera se processe por difusão de vapor, o que ocorre no solo muito argiloso desde o segundo dia do início do processo de evaporação.

No vigésimo primeiro dia simulou-se uma irrigação aplicando-se uma lâmina d'água de $20 \mathrm{~mm}$ em todos os tratamentos. Nos tratamentos com $10.000 \mathrm{~kg} \mathrm{ha}^{-1}$ de resíduo, para os solos areia franca e muito argiloso, ocorreu drenagem nas colunas de solo; portanto, os dados foram descartados para este dia. Para os tratamentos com $5.000 \mathrm{~kg} \mathrm{ha}^{-1}$ de resíduo não ocorreu drenagem, e, sem aumento significativo da evaporação, após a
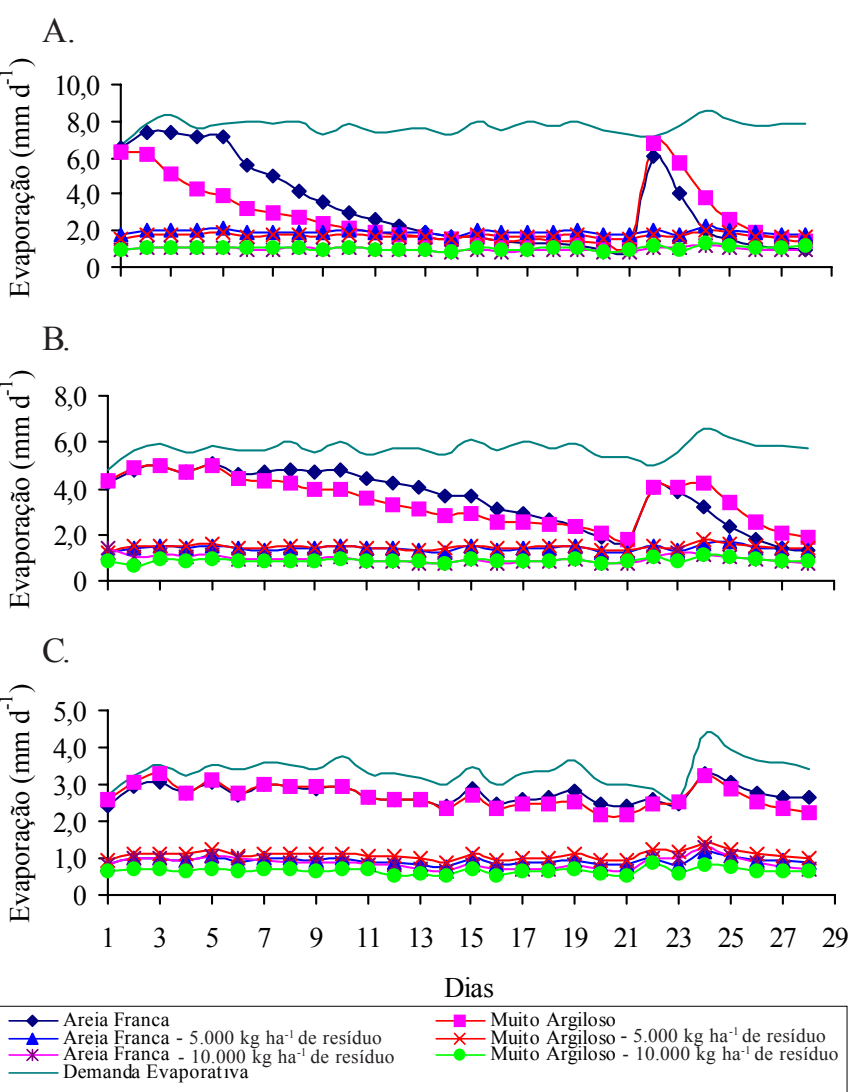

Figura 2. Evaporação da água do solo sem e com resíduo da cultura do milho sobre a superfície deste, em colunas de PVC, para uma demanda evaporativa em torno de (A) $8 \mathrm{~mm} \mathrm{~d}^{-1}$, (B) $6 \mathrm{~mm} \mathrm{~d}^{-1} \mathrm{e}$ (C) $3 \mathrm{~mm} \mathrm{~d}^{-1}$

aplicação da lâmina d'água, como aconteceu para os solos sem resíduo, o que pode ser observado na Figura 2A, pois os valores da evaporação foram próximos aos do início do processo em que o solo foi saturado; no entanto, a evaporação do solo muito argiloso foi superior à do solo areia franca, situação esta distinta do processo no início, quando o solo estava saturado.

A redução na taxa de evaporação da água do solo para a demanda evaporativa de aproximadamente $8 \mathrm{~mm} \mathrm{~d}^{-1}$ (Fig. 2A) ocorrida nos primeiros dias, é igual à obtida por Lascano \& van Bavel (1986).

A evaporação nos tratamentos sem resíduo, para a demanda evaporativa de $8 \mathrm{~mm} \mathrm{~d}^{-1}$, foi superior à do tratamento com 5.000 $\mathrm{kg} \mathrm{ha}^{-1}$ de resíduo até o $11^{\circ}$; a partir deste dia, a evaporação do tratamento sem resíduo apresentou valores inferiores.

\section{Demanda evaporativa de $6 \mathrm{~mm} \mathrm{~d}^{-1}$}

A evaporação da água do solo para demanda evaporativa de $6 \mathrm{~mm} \mathrm{~d}^{-1}$ (Fig. 2B) apresentou diferenças no comportamento, quando comparada com a demanda de $8 \mathrm{~mm} \mathrm{~d}^{-1}$ (Fig. 2A). No período inicial, as evaporações ocorridas nos dois solos foram praticamente iguais até o sexto dia, porém a partir daí a evaporação da água no solo areia franca superou a evaporação no solo muito argiloso, até o $20^{\circ}$ dia, enquanto para a demanda evaporativa de $8 \mathrm{~mm} \mathrm{~d}^{-1}$ a evaporação no solo areia franca foi superior à do solo muito argiloso (Fig. 2A). A evaporação dos tratamentos sem resíduo foi superior à do tratamento com 5.000 $\mathrm{kg} \mathrm{ha}^{-1}$ de resíduo, para todo o período. 
Após a aplicação da lâmina d'água de $20 \mathrm{~mm}$ no $21^{\circ}$ dia, a evaporação do solo muito argiloso foi superior à do solo areia franca, o que contrasta com o período inicial do experimento, quando o solo foi saturado e deixado drenar por cinco dias, tendo o solo areia franca apresentado evaporação superior.

\section{Demanda evaporativa de $3 \mathrm{~mm} \mathrm{~d}^{-1}$}

Para a demanda evaporativa de $3 \mathrm{~mm} \mathrm{~d}^{-1}$, (Fig. 2C), observouse que a evaporação da água no solo permaneceu no primeiro estágio de evaporação, no período de coleta de dados do experimento, que foi de 21 dias; esses resultados são concordantes com os de Bond \& Willis (1970) e Reichardt (1968).

A taxa de evaporação nos tratamentos com solo descoberto foi aproximadamente três vezes a dos tratamentos com cobertura de resíduo. O tratamento com $10.000 \mathrm{~kg} \mathrm{ha}^{-1} \mathrm{de}$ resíduo e solo areia franca, apresentou valores superiores aos dos demais tratamentos com resíduo, nos primeiros dias do experimento, pelo fato de nessas colunas de solo a drenagem não ter cessado após os cinco dias da saturação.

A taxa de evaporação da água do solo descoberto para demandas evaporativas reduzidas em torno de $3 \mathrm{~mm} \mathrm{~d}^{-1}$, aproxima-se do valor da demanda evaporativa.

\section{Evaporação nas duas classes de solo e para três demandas evaporativas}

A taxa de evaporação para a demanda evaporativa de 8 $\mathrm{mm} \mathrm{d}^{-1}$ apresentou queda acentuada nos primeiros dias. $\mathrm{O}$ tratamento com solo areia franca mostrou taxa de evaporação superior à do tratamento com o solo muito argiloso, até o $15^{\circ}$ dia. Para a demanda evaporativa de $6 \mathrm{~mm} \mathrm{~d}^{-1}$, o tratamento com o solo areia franca indicou taxas de evaporação superiores às do solo muito argiloso, a partir do quinto dia do início do processo.

As taxas de evaporação para as demandas evaporativas de 8 e $6 \mathrm{~mm} \mathrm{~d}^{-1}$, a partir dos sétimo e $17^{\circ}$ dias, respectivamente, foram inferiores às do tratamento com demanda evaporativa de $3 \mathrm{~mm} \mathrm{~d}^{-1}$ (Fig. 3). Quanto maior a demanda evaporativa, mais rapidamente aparecem fissuras no solo muito argiloso, para a demanda evaporativa de $3 \mathrm{~mm} \mathrm{~d}^{-1}$; o solo muito argiloso não apresentou fissuras.

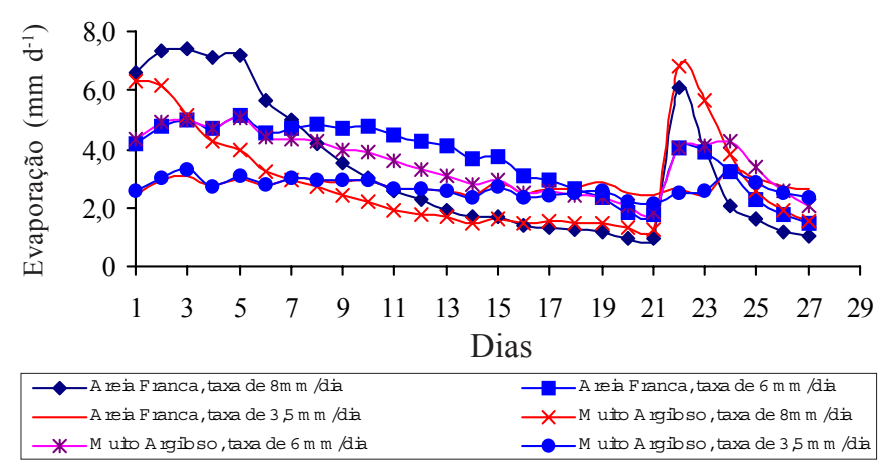

Figura 3. Evaporação da água do solo para os tratamentos

Os tratamentos com taxa de resíduo de $5.000 \mathrm{~kg} \mathrm{ha}^{-1}$ (Fig. 4A) apresentaram taxa de evaporação decrescente com a demanda evaporativa. Para a demanda evaporativa de $8 \mathrm{~mm} \mathrm{~d}^{-1}$, a taxa de evaporação do tratamento com solo areia franca foi maior que a do solo muito argiloso, o que não ocorreu para as outras duas demandas evaporativas.

As taxas de evaporação apresentaram valores muitos próximos, independentemente da demanda evaporativa. Para o tratamento areia franca e demanda evaporativa de $3 \mathrm{~mm} \mathrm{~d}^{-1}$ (Fig. 4B) a taxa de evaporação no início foi superior à dos demais, em razão da drenagem da coluna continuar após a retirada da cobertura plástica das colunas.

Na Tabela 2 estão dados da taxa média da evaporação da água do solo para um período de sete dias e sua relação com a demanda evaporativa média do período. A taxa média de evaporação para os solos descobertos foram em torno de $85 \%$ da demanda evaporativa, para os primeiros sete dias, relação esta próxima à citada por Jensen et al. (1990). A relação entre as taxas de evaporação para o solo descoberto mostra que, para a demanda evaporativa de $8 \mathrm{~mm} \mathrm{~d}^{-1}$, o solo argiloso apresentou valor muito abaixo da relação obtida no solo areia franca, enquanto para as outras demandas evaporativas ela permaneceu constante. Para os tratamentos com resíduo da cultura do milho, a taxa de evaporação para a demanda evaporativa de $8 \mathrm{~mm} \mathrm{~d}^{-1}$ foi de $13 \%$ para uma taxa de $10.000 \mathrm{~kg} \mathrm{ha}^{-1} \mathrm{de}$ resíduo, valor este abaixo dos obtidos em outras demandas evaporativas; todavia, o valor absoluto da evaporação da água do solo para todas as demandas evaporativas, para este tratamento, foi muito próximo evidenciando que, para esta condição, a evaporação independe do valor da demanda evaporativa, porém para os tratamentos com taxa de $5.000 \mathrm{~kg}$ ha $^{-1}$ de resíduo, o valor absoluto da evaporação da água do solo apresentou pequenos decréscimos com a redução da demanda evaporativa.

A redução na evaporação da água do solo, promovida pelo resíduo da cultura, traria uma economia de água e de energia para o acionamento do sistema de irrigação, no período inicial de instalação de uma cultura.
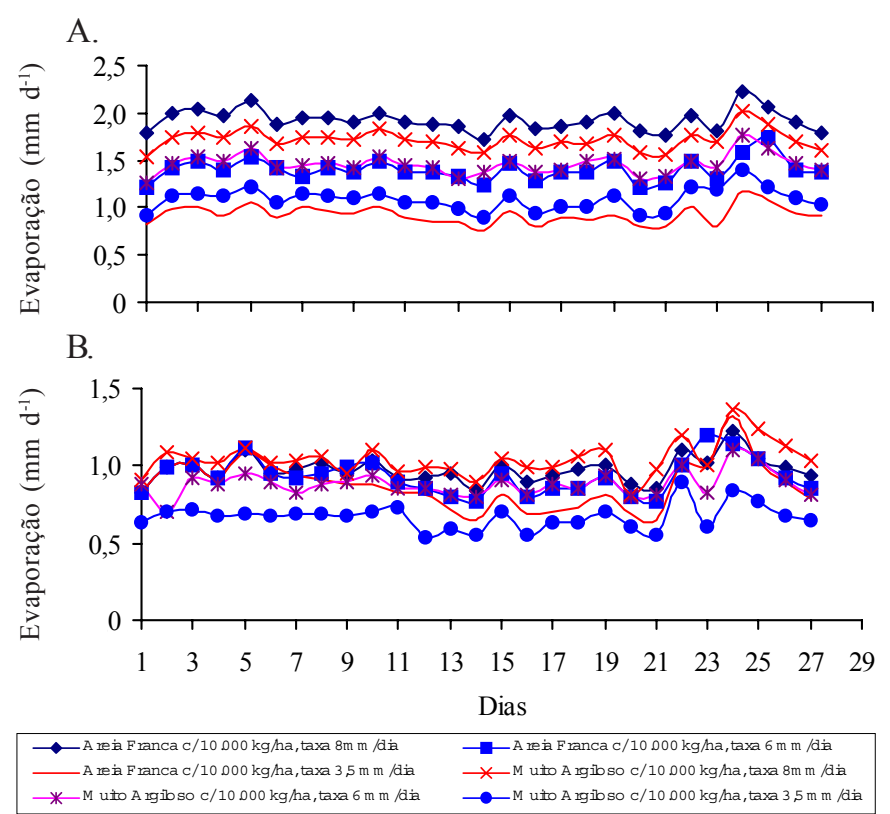

Figura 4. Evaporação da água do solo com (A) $5.000 \mathrm{~kg} \mathrm{ha}^{-1} \mathrm{e}$ (B) $10.000 \mathrm{~kg} \mathrm{ha}^{-1}$ de resíduo da cultura do milho, para os tratamentos 
Tabela 2. Taxas médias de evaporação nos tratamentos com relação às demandas evaporativas, para o período de sete dias

\begin{tabular}{|c|c|c|c|c|c|c|}
\hline \multirow{2}{*}{ Tratamentos } & \multicolumn{6}{|c|}{ Demanda Evaporativa $\left(\mathrm{mm} \mathrm{d}^{-1}\right)$} \\
\hline & 8 & 6 & 3 & 8 & 6 & 3 \\
\hline Solos e Taxas de Resíduo & \multicolumn{3}{|c|}{ Taxas $(\%)$} & \multicolumn{3}{|c|}{ Taxa de Evaporação $\left(\mathrm{mm} \mathrm{d}^{-1}\right)$} \\
\hline Areia franca & 85 & 85 & 86 & 6,6 & 4,7 & 2,8 \\
\hline Muito argiloso & 59 & 84 & 88 & 4,6 & 4,7 & 2,9 \\
\hline Areia franca com $5.000 \mathrm{~kg} \mathrm{ha}^{-1}$ de resíduo & 25 & 25 & 29 & 2,0 & 1,4 & 1,0 \\
\hline Muito argiloso com $5.000 \mathrm{~kg} \mathrm{ha}^{-1}$ de resíduo & 22 & 26 & 33 & 1,7 & 1,5 & 1,1 \\
\hline Areia franca com $10.000 \mathrm{~kg} \mathrm{ha}^{-1}$ de resíduo & 13 & 19 & 29 & 1,0 & 1,1 & 1,0 \\
\hline
\end{tabular}

* A drenagem não cessou após o início das pesagens

Analisando-se a Tabela 3, nota-se que a demanda evaporativa influenciou a quantidade de água evaporada em cada tratamento, considerando-se o solo descoberto e a quantidade de água evaporada nas colunas de solo, nos primeiros 21 dias. No tratamento com demanda evaporativa de $8 \mathrm{~mm} \mathrm{~d}^{-1}$, verificouse uma quantidade de água evaporada menor, quando comparada com a do tratamento com demanda evaporativa de $6 \mathrm{~mm} \mathrm{~d}^{-1}$. Para o solo muito argiloso, as quantidades de água evaporada nos tratamentos com demandas evaporativas de 8 e $3 \mathrm{~mm} \mathrm{~d}^{-1}$, foram iguais.

Tabela 3. Lâmina d'água evaporada em cada tratamento em 21 dias, em experimento com resíduo da cultura do milho

\begin{tabular}{lrcc}
\hline \multirow{2}{*}{\multicolumn{1}{c}{ Tratamentos }} & $\begin{array}{r}\text { Demanda Evaporativa } \\
\left(\mathrm{mm} \mathrm{d}^{-1}\right)\end{array}$ \\
\cline { 2 - 4 } \multicolumn{1}{c}{ Solos e Taxas de Resíduo } & \multicolumn{1}{c}{8} & \multicolumn{1}{c}{3} \\
\hline Areia franca & 74,22 & 82,0 & 57,2 \\
Muito argiloso & 56,4 & 74,2 & 56,4 \\
Areia franca com 5.000 kg ha ${ }^{-1}$ de resíduo & 40,2 & 28,9 & 19,0 \\
Muito argiloso com 5.000 kg ha ${ }^{-1}$ de resíduo & 35,7 & 30,1 & 22,2 \\
Areia franca com 10.000 kg ha ${ }^{-1}$ de resíduo & 20,4 & 19,8 & 18,6 \\
Muito argiloso com 10.000 kg ha de resíduo $^{-1}$ & 21,1 & 18,1 & 13,6 \\
Demanda evaporativa & 160,8 & 119,1 & 69,6 \\
\hline
\end{tabular}

Considerando-se o tratamento com $5.000 \mathrm{~kg} \mathrm{ha}^{-1}$ de resíduo da cultura, observou-se que a demanda evaporativa influenciou a quantidade de água evaporada durante o experimento. A quantidade de água evaporada nos tratamentos com demandas evaporativas de 6 e $3 \mathrm{~mm} \mathrm{~d}^{-1}$, correspondeu a 71 e $47 \%$, respectivamente, da quantidade evaporada no tratamento com a demanda de $8 \mathrm{~mm} \mathrm{~d}^{-1}$.

Levando-se em conta o tratamento com $10.000 \mathrm{~kg} \mathrm{ha}^{-1} \mathrm{de}$ resíduo da cultura, vê-se que a demanda evaporativa não influenciou a quantidade de água evaporada durante o experimento, para as demandas evaporativas de 8 e $6 \mathrm{~mm} \mathrm{~d}^{-1}$; já para a demanda evaporativa de $3 \mathrm{~mm} \mathrm{~d}^{-1}$ para o solo areia franca, a quantidade de água evaporada foi muito superior à do tratamento com solo muito argiloso, em razão de nos primeiros dias de pesagem nas colunas de solo areia franca a drenagem do solo ter sido pequena, porém a drenagem continuava ocorrendo, pois a parte externa do fundo das colunas estava úmida.

A quantidade de água retida pelo resíduo após a aplicação da lâmina d'água de $20 \mathrm{~mm}$, está apresentada na Tabela 4. Para a condição em que o resíduo foi imerso em água, houve aumento na quantidade retida, de apenas $0,2 \mathrm{~mm}$ para $10.000 \mathrm{~kg} \mathrm{ha}^{-1} \mathrm{de}$ resíduo e, para a condição de sistemas de irrigação com alta freqüência de aplicação de água, a quantidade de água retida pelo resíduo pode ser significativa, o que faz com que a proporção de água evaporada seja relativamente alta.

Tabela 4. Quantidade de água retida pelo resíduo após a aplicação de lâmina de $20 \mathrm{~mm}$

\begin{tabular}{cc}
$\begin{array}{c}\text { Quantidade de Resíduo } \\
\left(\mathrm{kg} \mathrm{ha}^{-1}\right)\end{array}$ & $\begin{array}{c}\text { Lâmina Retida pelo Resíduo } \\
(\mathrm{mm})\end{array}$ \\
\hline 10.000 & 1,8 \\
6.300 & 1,4 \\
4.800 & 1,2 \\
\hline
\end{tabular}

\section{CONCLUSÕES}

1. A taxa de evaporação da água do solo descoberto apresentou comportamento distinto para as três demandas evaporativas utilizadas.

2. Para a demanda evaporativa de aproximadamente $3 \mathrm{~mm} \mathrm{~d}^{-1}$, o tratamento com solo descoberto permaneceu no primeiro estágio de evaporação, pelo período de 21 dias do experimento.

3. Para a taxa de resíduo de $100 \%$ da matéria seca, a demanda evaporativa teve pequena influência na redução na evaporação da água do solo, que foi de aproximadamente $20 \%$ da evaporação ocorrida no tratamento com solo descoberto, para as duas classes de solo.

4. A redução na evaporação da água do solo promovida pelo resíduo da cultura dispostos sobre a superfície do solo, em sistema irrigado em plantio direto, permitiria uma aplicação de lâmina d'água menor, no início do crescimento da cultura, propiciando economia de água e energia.

\section{LITERATURA CITADA}

Alencar, C.A.B. Intensidade de aplicação e escoamento superficial em irrigação com pivôs centrais de baixa e de média pressão. Viçosa: UFV, 1988. 87p. Dissertação Mestrado Al-Khafaf, S.; Wierenga, P.J.; Willians, B.L. Evaporative flux from irrigated cotton as related to leaf area index, soil water and evaporative demand. Agronomy Journal, Madison, v.70, p.912-917, 1978.

Alvarenga, A.P. Resposta da planta e do solo ao plantio direto e convencional, de sorgo e feijão, em sucessão a milho, soja e crotalária. Viçosa: UFV, 1996. 162p. Tese Doutorado 
Andrade, P.A. Compaction del suelo y sistemas de laboreo: Irespuestas del crecimiento del girasol a la compactacion del suelo. II- influencia del sistema de laboreo la producion de soja en segunda cosecha. Cordoba: Universidad de Cordoba, 1992. 198p. Tesis Doctoral

Bond, J.J.; Willis, W.O. Soil water evaporation: first stage drying as influenced by surface residue and evaporation potential. Soil Science Society of America Journal, Madison, v.34, p.924-928, 1970.

Bordovsky, J.P.; Lyle, V.M.; Keeling, J.W. Crop rotation and tillage effects on soil water and cotton yield. Agronomy Journal, Madison, v.86, p.1-6, 1994.

Jensen, M.; Burman, R.D.; Allen, R.G. Evapotranspiration and irrigation water requeriments. New York: ASCE, 1990. 332p. Manuals and reports on engenineering practice, 70

Klocke, N.L.; Heermann, D.F.; Duke, H.R. Measurements of evaporatiion and transpiration with lysimeters. Transactions of the ASAE, St. Joseph, v.28, p.183-189, 1985.

Lascano, R.J.; Baumhardt, R.L. Effects of crop residue on soil and plant water evaporation in dryland cotton system, Theoretical and Apllied Climatology, Vienna, v.54, p.69-84, 1996.

Lascano, R.J.; van Bavel, C.H.M. Simulation and measurement of evaporation from a bare soil. Soil Science Society of America Journal, Madison, v.50, p.1127-1133, 1986.
Lascano, R.J.; van Bavel, C.H.M.; Hatfiled, J.L.; Upchurch, D.R. Energy and water balance of a sparse crop: Simulated and measured soil crop evaporation. Soil Science Society of America Journal, Madison, v. 51, p.1113-1121, 1987.

Reichardt, K. Estudo do processo da evaporação da água do solo. Piracicaba: ESALQ/USP, 1968, 95p. Tese Livre Docência

Ritchie, J.T. Model for predicting evaporation from a row crop with incomplete cover. Water Resources Research, Washington, v.8, n.5, p.1204-1213, 1972.

Ritchie, J.T.; Jonhson, B.S. Soil and plant factors affeting evaporation In: Stewart, B.H.; Nielson, D.R. (eds) Irrigation of agricultural crops. Madison. Agronomy Society of Americana, 1990. p.363-390, Agronomy Monograph, 30

Tanner, C.B. ; Jury, W.A. Estimating evaporation and transpiration from a row crop during incomplete cover. Agronomy Journal, Madison, v.68, p.239-243, 1976.

Unger, P.W. Straw-mulch rate effect on soil water storage and sorghum yield. Soil Science Society of America Journal, Madison, v. 42, p.486-91, 1978.

Unger, P.W. Residue management for winter wheat and grain sorghum production with limited irrigation. Soil Science Society of America Journal, Madison, v. 58, p.537-542, 1994.

Unger, P.W.; Wiese, A.F. Managing irrigated winter wheat residues for water storage and subsequent dryland grain sorghum production. Soil Science Society of America Journal, Madison, v. 43, p.582-8, 1979. 